\title{
Diagnostics of the development of independence of future teachers of vocational training
}

\author{
I.B. Bicheva ${ }^{1 *}$, S.N. Kaznacheeva ${ }^{2}$, and G.A. Paputkova ${ }^{3}$ \\ ${ }^{1}$ K. Minin Nizhny Novgorod State Pedagogical University, Nizhny Novgorod, Russia \\ ${ }^{2}$ K. Minin Nizhny Novgorod State Pedagogical University, Nizhny Novgorod, Russia \\ ${ }^{3}$ K. Minin Nizhny Novgorod State Pedagogical University, Nizhny Novgorod, Russia
}

\begin{abstract}
The authors consider the process of diagnosing the development of the independence of future teachers of vocational training. The authors underline the necessary to study the level of development of the independence of future teachers of vocational training. Nowadays, it is important to have a competitive professional teacher who is able to solve educational and professional tasks effectively. Three levels of formation of independence of future teachers of vocational training (low (reproductive), medium (reconstructive), high (creative, proactive) are determined in it. There is their description. There are the results of diagnostics of the level of independence formation among full-time and part-time students. The authors present a comparative analysis of the level of its formation among second-year students. The forms and methods of increasing the level of development of independence of future teachers of vocational training are offered in the article. The conclusion is made: improving the quality of organization of independent study is a promising direction of professional training of future teachers of vocational training. The correct organization of independent study provides systematic and consistent support of teachers in the process of educational activities, aimed at the development of independence, individual advancement, awareness of the prospects for personal and professional development. Therefore, the possibility of future career growth and the increase in the competitiveness of teachers in the modern professional situation is increasing. The prospect of further research involves the development of a model for managing the independent study of students - future teachers of vocational training.
\end{abstract}

\section{A problem statement}

The modern educational situation makes special demands on the future teachers of vocational training as future-oriented competitive specialist who are able to demonstrate the formed competencies [1-5]. One of the important and demanded qualities of a teacher is his or her independence. Its development determines the achievement of the necessary quality,

\footnotetext{
*Corresponding author: ipcs-profped@yandex.ru
} 
both in the process of obtaining education, and in the conditions of future professional activity. The independence of the person gives the possibility to realize the tasks most effectively, showing purposefulness, activity, criticality, initiative, the ability to consciously acquire information, apply existing knowledge in new conditions. These aspects are disclosed in the studies of N.A. Aleksev [6], E.F. Zeer [7], E.A. Klimov [8], and other scientists.

The influence of the level of independence development on the personal self-education is noted in the article written by P.I. Pidkasisty, L.M. Fridman, M.G. Garunov [9]. Such components of cognitive activity as understanding in cognition of new things, vision and formulation of a problem, the ability to use real knowledge and methods of activity to solve it, plan their activities, analyze various options and select the most optimal, etc. are characterized in this context.

E.I. Alferova and E.F. Zeer [10], S.I. Makarov and E.V. Buntova [11], L.A. Odintsova and O.Yu. Grigorieva [12], G.A. Pichugina [13], A.I. Ryaboshapka and N.A. Shalaginova [14] note the significance of the independence development as a key competence in achieving educational results in the context of lifelong education and competence-based approach in their works.

In addition, the Federal State Educational Standard of Higher Education in various areas and levels of training (bachelor's, master's) indicates the need for the formation of independence and a certain level of professional competence, which is requested by employers and the modern professional and educational situation from future teachers of vocational training.

An increase in the share of independent activities (up to $50 \%$ in bachelor training programs and up to $70-75 \%$ in master's educational programs) presupposes a high level of individual independence and responsibility for the result of self-training $[15,16]$. It depends on the students' awareness of their involvement in the results of professional training and their consequences, the degree of activity, the ability to set realistically achievable goals, how to plan and determine the ways of their activities, using a variety of resources without assistance from others. According to a study by S.N. Kaznacheeva, N.V. Bystrova, N.M. Grigoryan, K.D. Murygina, «more than $60 \%$ of students note the understanding of its significance, increasing self-organization and self-control as an effective condition for organizing independent study» [17, p. 44].

There are interesting publications that reveal the problem of organizing independent study with students of different forms of education. The successful organization of independent study with students is a condition for the independence development, the formation of interest and motivational readiness for learning / self-study, including the use of distance technologies [18-21].

Scientists prove the need to perform a set of conditions that must be met in the organization of the independent activity of students and ensure an increase in its quality. Firstly, the task for independent study should consist of a descriptive part with the definition of the goal, form, and formed competencies (educational results).

Secondly, for any task type it is necessary to prepare a list of recommended literature, including open information educational resources.

Thirdly, the implementation of independent study should be represented by a specific educational product (diagram, lecture notes, glossary, presentation, etc.) with delivery dates and form of its presentation.

Fourthly, the assessment of independent study is based on the criteria and indicators of assessment: quantitative (conformity of the volume of the studied material to the given material, the degree of completeness and correct solution of the problem, conformity with the professional standard) and qualitative (the degree of manifestation of activity, the level 
of training material design, the presence of well-grounded and reasoned conclusions, elements of novelty, etc.).

Thus, the development of personal independence within the problem of professional training of a future teacher of vocational training should be considered as a condition of its effectiveness. This is due to the requirements of higher education and the requests of potential employers because a high level of independence provides not only the achievement of the necessary qualifications, but also the demonstration of personal creativity in the process with given educational and professional tasks. Important features of the independence of a future teacher of vocational training are the constant desire to analyze and improve their knowledge and skills, use them creatively as well as self-directed behavior, originality of thinking, a sufficient level of independence, responsibility and objectivity. These characteristics enable a future teacher of vocational training to take great part in research and project activities in the process of vocational training, to demonstrate their communicativeness, ability to reflect, individuality of self-education.

\subsection{The objective of the work}

The aim of this article is to study the level of development of independence of future teachers of vocational training.

Tasks:

- to determine the level of development of independence of future teachers of vocational training and give their characteristics;

- to diagnose the levels of development of independence of future teachers of vocational training and analyze the results;

- to offer forms and methods of increasing the independence of future teachers of vocational training.

\section{Materials and the results of the research}

After consideration of the theoretical aspects of the problem of the development of independence, we will describe the process of diagnosing the level of development of independence of future teachers of vocational training.

Students of the field of study «Professional training (by industry)» at the Nizhny Novgorod State Pedagogical University named after K. Minin (at the beginning of the 2020-2021 academic year) took part in diagnostics of the level of independence formation.

Students of the 2 nd and 4 th courses of full-time ( 40 people) and part-time ( 70 people) forms of education participated in the research.

We have studied: awareness of the importance of independent study in the general system of professional training, the need for new knowledge and ways to acquire it, the ability to work with information sources and highlight essential information, to set a goal, to plan, to organize and regulate independent study, to do self-assess the results.

We studied the level of development of independence among respondents according to three levels: low (reproductive), medium (reconstructive), high (creative, proactive) (Table).

The results of the study at the beginning of the academic year show that students of all forms of education have a low level of development of independence in the second year (Fig. 1). 
Table. Levels of independence formation.

\begin{tabular}{|c|c|}
\hline $\begin{array}{c}\text { Levels of } \\
\text { independence } \\
\text { formation }\end{array}$ & Level characteristic \\
\hline 1 & 2 \\
\hline $\begin{array}{l}\text { low } \\
\text { (reproductive) } \\
\text { level }\end{array}$ & $\begin{array}{l}\text { A student does not understand the importance of independent study. There is } \\
\text { the ability to self-knowledge, he or she wants to get new knowledge but ways } \\
\text { of acquiring it are not expressed at a student. A student reproduces the basic } \\
\text { knowledge of the discipline. He or she does not use or rarely uses scientific and } \\
\text { methodological literature, information sources to complete independent tasks. } \\
\text { The student has difficulties in formulating and setting goals for independent } \\
\text { study, planning methods and organizing self-study. He or she is not active in } \\
\text { discussion of basic knowledge. A student does not ask the teacher for additional } \\
\text { advice and does not take part in communication with other classmates in the } \\
\text { process of independent study. A student does not know how to objectively } \\
\text { assess his or her potential in the process of performing independent study, } \\
\text { overestimates or underestimates the achieved result. Self-regulation is not } \\
\text { formed: he or she does not make volitional efforts to overcome difficulties in } \\
\text { the process of performing independent study. }\end{array}$ \\
\hline $\begin{array}{l}\text { medium } \\
\text { (reconstructive) } \\
\text { level }\end{array}$ & $\begin{array}{l}\text { A student understands the importance of independent study as a teacher's } \\
\text { requirement. A student has the ability for self-knowledge, wants to get new } \\
\text { knowledge; ways of its acquiring are manifested selectively to certain topics of } \\
\text { the discipline. A student has basic knowledge of the discipline. It could be } \\
\text { noted partly exploratory independent study at assimilation of new knowledge. } \\
\text { A student does not use scientific and methodological literature, information } \\
\text { sources for performing independent tasks constantly. A student does not } \\
\text { understand the aims of independent study enough, he or she formulates them } \\
\text { not precisely. The student chooses the wrong ways of independent study, the } \\
\text { chosen actions do not influence the solution of the set goals and objectives. } \\
\text { Realization of an independent study plan leads to a wrong or incomplete result. } \\
\text { He or she discusses basic knowledge actively. Sometimes he or she asks for } \\
\text { help to the teacher to clear the correctness of the independent study and is } \\
\text { included in communication with other classmates in the process of independent } \\
\text { study. A student makes some mistakes when assessing his or her possibilities in } \\
\text { the process of performing independent study. He or she can overestimate or } \\
\text { underestimate the received result. Self-regulation is partially formed: a student } \\
\text { can make volitional efforts to overcome difficulties in the process of } \\
\text { performing independent study which is interested for him or her. }\end{array}$ \\
\hline $\begin{array}{l}\text { high (creative, } \\
\text { initiative) level }\end{array}$ & $\begin{array}{l}\text { A student realizes the importance of independent study as a way of self- } \\
\text { management of professional development. He or she has the ability for self- } \\
\text { knowledge. This ability is expressed steadily and aimed at achieving } \\
\text { educational results. A student uses basic knowledge of the discipline } \\
\text { consciously; wants to get new knowledge, knows ways to acquire it. He or she } \\
\text { constantly uses scientific and methodological literature, various information } \\
\text { sources to complete independent tasks. The goals of independent study are } \\
\text { realized and formulated concretely. A student plans the methods of independent } \\
\text { study purposefully, including real actions that influence the achievement of the } \\
\text { set goals, including creative. Realization a plan of an independent study leads } \\
\text { to a high-quality result. There is the novelty of the result of independent study. } \\
\text { He or she shows initiative in discussing basic and acquired knowledge, ability } \\
\text { to critically analyze the new studied content. A student constantly interacts with } \\
\text { the teacher and actively communicates with other classmates during performing } \\
\text { independent study. A student can objectively assess his or her possibilities in } \\
\text { the process of doing independent study and analyze the result. Self-regulation is } \\
\text { formed: there is volitional efforts to overcome difficulties in the process of } \\
\text { performing independent study. }\end{array}$ \\
\hline
\end{tabular}




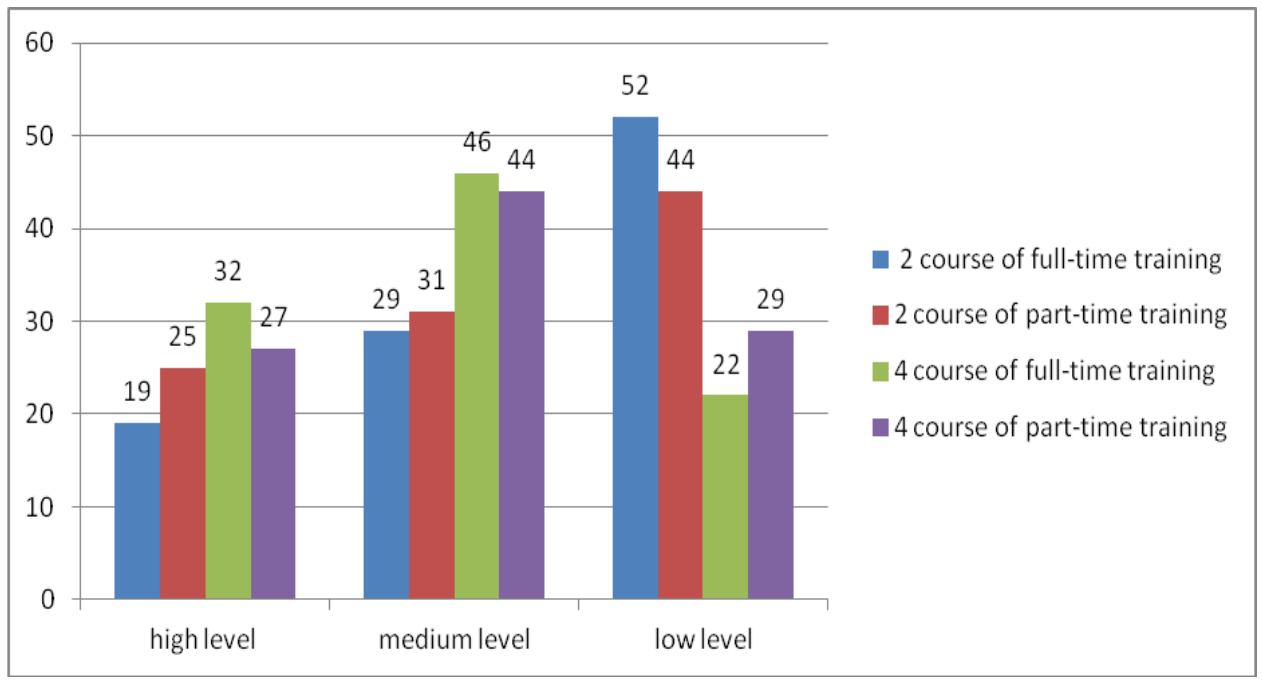

Fig. 1. Results of diagnostics of the level of development of independence among students of vocational training, $\%$.

Moreover, this indicator is higher in full-time training (52\%) than in part-time training $44 \%$. The reasons for this situation are students cannot work independently and do not understand the importance of self-education. Besides, a lot of full-time first-year students keep the skill of «school» learning, which did not require to do things on his or her own. So, it increases the importance of targeted career guidance including methods of teaching independent types of activities [22]. Only $29 \%$ of full-time students and $31 \%$ of part-time studies in the second year demonstrate a medium level. In average $22 \%$ of students of all forms training of the second year have a high level. The number of students with a medium level increases significantly in the final year of study (in full-time training - $46 \%$, in parttime training - 44\%). $32 \%$ of full-time students and $27 \%$ of part-time students have a high level in the senior courses of study. $22 \%$ of full-time students and $29 \%$ of part-time students have a low level in the senior courses of study.

Analyzing the data obtained, we note that by the senior years the majority of respondents understand the importance of developing their independence. In their opinion, this will allow them to be more independent, provide the necessary self-organization and self-control in their professional activities. At the same time, ways of developing independence are difficult. There are such typical answers for part-time students $(37 \%$ of the respondents) as «we need an independence but we do not have enough time», «if there is a study plan, then how to show our independence?».

Among the identified problems, it is necessary to note a rather low level of development of goal-setting, planning, self-organization, self-reflection among students. The lack of involvement of each student in an independent professional and educational process leads to the fragmentation of the received knowledge, misunderstanding of education and selfeducation as a way of life; inability to use the educational information space of the Internet correctly (students often use Internet sites where they can find ready-made methodological developments but they are not always high-quality).

Our research also found that students of all forms of learning need teacher guidance to improve their independent study. For example, the majority of respondents to the question, «What conditions does the quality of your independent study depend on?» pointed to «the importance of the teacher's attention to their results», «the possibility of joint debate on the results». Half of the respondents believe that teacher should stimulate them to independent study of new content and complete tasks. 
Therefore, in order the independent study of students provides the gaining of the necessary personal experience for future professional activities, promotes individualization and an operational assessment of educational results, it is necessary to think over various forms and methods of its support, guided by such principles as interdependence, consistency and continuity, active involvement and objectivity.

The role of the teacher as a manager is increased when organizing independent study from the position of accompanying students. The teacher realizes the functions of goalsetting, planning, execution, communication, control and reflection in the process of selfpreparation. Besides, it increases the role of purposeful managerial influence, design of various options for independent study, constructive interaction, reflective discussion.

We note that independent study is an educational task for students. It is planned in each section (module) of the academic discipline. Methodological and didactic support, criterial evaluation tools are included in it [23-25]. It could be express survey on the topic, reflexive reasoning to find out the level of the awareness of understanding a new topic, plan a lecture using key concepts. In the process of such work, it could be the development of the voluntary attention. More over it leads to more concentration on new terms or new information, their systematization, as well as the allocation of problematic aspects «I understand this, but this issue is difficult» and the determination of individual ways of independent study.

It should be developed the methods of organizing the independent study taking into account the individual educational strategies of a particular student, his or her personal qualities. Besides the professional interests of students are determined both by the content of the studied direction, and their achievement of success in the process of studing methods performed to master or consolidate new material, as well as the possibility of constructive communication. This conclusion is consistent with the findings of scientists. For example, G.I. Ibragimov underlines the role of management in the success of students' independent study and allocates «pedagogical means at all stages of its implementation, taking into account: the readiness of students for this work; organic inclusion of independent study as the leading form of organizing educational activities in the modern information and educational environment; the use of design and research models for organizing independent activities of students; co-creation of teachers and students» [26, $\mathrm{p}$. 57].

S.N. Sorokoumova, S.P. Elshansky, E.B. Puchkova, Yu.V. Sukhovershina's research proves the need for a differentiated approach to students based on their individual style characteristics. S.N. Sorokoumova, S.P. Elshansky, E.B. Puchkova and Yu.V. Sukhovershina's research proves the need for a differentiated approach to students based on their individual style characteristics. The authors note that the pronounced predominance «in the group of students of some characteristic cognitive style, which the teacher will be guided by, for those students whose individual characteristics «fall out», personalization of training is necessary, taking into account their specific characteristics (for example, in the format of individual lessons or attachment to the best students)» $[27$, p. 6].

So, taking into account the individual style characteristics of students, it is possible to provide the necessary quality of professional training, including performing independent types of study. It is advisable to develop individually differentiated tasks. Their content and implementation will allow students with different learning styles to realize their cognitive interests (for example, develop a project, a notes of a class (lesson), recommendations (memo), solve a professional situation, a case-task, prepare a presentation and etc.). The use of such types of tasks contributes to the creation of situations in which students realize and get a positive experience of their own transformation and development. It can be offered to students the preparation of an analytical (abstract) review on a scientific and theoretical problem, a list of literature (scientific, methodological, bibliographic) on the topic, 
preparation of a report (essay) during the period of independent extracurricular study. Besides they can make up questions for consultation with a teacher, perform the test work, develop didactic manual. Performing these types of work, information sources of knowledge play an increasing role, «among which the teacher occupies an active, but not the only place», helping to correctly navigate in modern information flows [28]. Increasing the role of information in the process of independent learning of knowledge increases the responsibility of students to study actual areas of professional training, it teaches them to purposefully do in self-education, develops motivational and cognitive activity in the process of information exchange. Thus, a mode of individual self-development is provided, the level of meaningful study and analysis of various information resources is increased. Teachers broaden opportunities of modifying of the professional training content through generalization, comparison of information sources, their differentiation according to the level of complexity. In addition, the modern information space allows you to create your own methodological and didactic developments, interactive funds of diagnostic and evaluation tools of various levels of complexity.

Control/self-control over the implementation of independent study involves the use of various assessment tools, including in the conditions of the electronic educational environment of the university, as well as the demonstration of reporting materials at seminars in the form of presentations, master classes, presentation of the results of research and design work, etc.

\section{Conclusions}

Improving the quality of the organization of independent study is a promising direction in the professional training of future teachers of vocational training. It is aimed at developing independence, individual advancement, awareness of the prospects for personal and professional development and, as a result, it increases the opportunities for future career growth and increasing competitiveness in the modern professional situation.

Various forms and methods of independent study contribute to the formation of a conscious attitude of students to independent knowledge and the gaining of experience in self-educational activity. Their variability ensures the inclusion of each student in the selfknowledge educational process based on the principles of individualization and differentiation, contributing to the accumulation of personal experience of self-educational activity, as it provides for each student the most suitable way of independent study that supports their educational and future professional goals. In addition, individualization and differentiation of the performance of independent types of studying and their following assessment make students to more actively and purposefully show their independence in the preparation process working with information sources.

The use of high-quality electronic educational resources, methods of active self-study and self-assessment techniques have the great importance. They strengthen the responsibility of students in matters of goal-setting, planning and organization of their own professional development in terms of understanding the results of vocational training and their relevance in the future professional field of activity, provide individualization. Possession of the skills of remote work increases their responsibility for studying the current areas of professional training, teaches them to purposefully engage in selfeducation, develops motivational and cognitive activity in the process of information exchange. This ensures the mode of individual self-development, increases the level of meaningful study and analysis of various information resources. Teachers have the opportunity to expand the possibilities for modifying the content of professional training through generalization, comparison of information sources, their differentiation by level of complexity. In addition, the modern information space allows you to create your own 
methodological and didactic developments, interactive funds of diagnostic and evaluation tools of various levels of complexity. The prospect of further research involves the development of a model for managing the independent study of students - future teachers of vocational training.

\section{References}

1. S.M. Markova, S.A. Tsyplakova, C.P. Sedykh, A.V. Khizhnaya, O.N. Filatova, Forecasting the development of professional education, Lecture Notes in Networks and Systems (2020)

2. N.V. Belinova, I.B. Bicheva, A.Y. Vershinina, T.G. Khanova, A.V. Khizhnaya, Innovation and education: technologies and perspectives, Journal of Advanced Research in Dynamical and Control Systems (2020)

3. I.B. Bicheva, S.N. Kaznacheeva, Conditions for the formation of students' readiness for competitive professional activity (Science and practice of regions, 2019)

4. A.M. Novikov, Professional education: aspiration to the future, Problems of modern education (2012)

5. G.A. Paputkova, T.F. Krasnopevtseva, Modern approaches to the formation of general cultural competence of bachelors of pedagogical education, Modern problems of science and education (2014)

6. N.A. Alekseev, Psychological conditions and mechanisms of activity of the subject of learning, Bulletin of the Chelyabinsk State Pedagogical University (2015)

7. E.F. Zeer, V.S. Tretyakova, I.A. Kurochina, T.D. Bukovei, T.V. Beresneva, Teachers competitiveness at different stages of professional development, Humanities and Social Sciences Reviews (2019)

8. E.A. Klimov, On the development of independence, Questions of psychology (2011)

9. P.I. Pidkasisty, L.M. Fridman, M.G., Garunov Psychological and didactic reference book of a higher school teacher (Moscow: Pedagogical Society of Russia, 1999)

10. E.I. Alferova, E.F. Zeer, Psychological characteristics of the responsibility of teachers in the process of professional development (Education and Science, Izvestiya URO RAO, 2007)

11. S.I. Makarov, E.V. Buntova, Organization of independent work of students within the framework of the competence-based approach to learning Samara Scientific Bulletin (2017)

12. L.A. Odintsova, O.Yu. Grigorieva, Independent work of undergraduate students as a means of including them in continuous education, Modern problems of science and education (2017)

13. G.A. Pichugina, Independent activity as a means of developing self-education, Baltic Humanitarian Journal (2018)

14. A.I. Ryaboshapka, N.A. Shalaginova, Contact work of teachers and students in the electronic information and educational environment of the university as a factor in the formation of general cultural and professional competencies. (News of the Southern Federal University, Pedagogical sciences, 2018)

15. L.G. Pak, Out-of-class activity as a means of forming social and professional responsibility of university students, Bulletin of the Orenburg State Pedagogical University (Electronic scientific journal, Russia, access mode: http://vestospu.ru/archive/2019/articles/20_32_2019.pdf) 
16. S.S. Bykova, Formation of professional responsibility of a future teacher: psychological and pedagogical context., Bulletin of the Vyatka State University (2018)

17. S.N. Kaznacheeva, N.V. Bystrova, N.M. Grigoryan, K.D. Murygina, The essence and content of independent work of students in a higher educational institution, Karelian scientific journal (2019)

18. N.V. Bystrova, S.N. Kaznacheeva, O.V. Yudakova, Independent work as a means of developing interest in learning among university students, Problems of modern pedagogical education (2020)

19. S.N. Kaznacheeva, T.V. Perova, Problems of the formation of independent cognitive activity of part-time students, Vestnik of Minin University (2017)

20. E.A. Chelnokova, S.N. Kaznacheeva, Conditions for the effectiveness of independent work of students, Problems of modern pedagogical education (2017)

21. I.B. Bicheva, O.M. Filatova, Formation of a teacher-leader in the educational process of the university, Vestnik of Minin University (2017)

22. A.S. Kurbatova, I.B. Bicheva, N.V. Ivanova, S.A. Zaitseva, L.V. Krasilnikova, Career guidance problem as a systemic problem in Russian society, REVISTA INCLUSIONES (2020)

23. M.L. Gruzdeva, O.I. Vaganova, S.N. Kaznacheeva, N.V. Bystrova, A.V.Chanchina, Modern Educational Technologies in Professional Education, Lecture Notes in Networks and Systems (2020)

24. M.N. Bulaeva, O.I. Vaganova, N.B. Vorobyov, Z.V. Chaikina, L.Y. Shobonova, Technology of Pedagogical Workshops in Professional Education, Lecture Notes in Networks and Systems (2020)

25. O.I. Vaganova, A.A. Korostelev, E.A. Chelnokova, A.V. Bugoslavskaya, A.Y. Melnikova, Technology for compiling supporting abstracts in the organization of students' independent work, AMAZONIA INVESTIGA (2020)

26. G.I. Ibragimov, Independent study of students: problems of organization and conditions of stimulation. (Alma mater: Bulletin of the higher school, 2018)

27. S.N. Sorokoumova, S.P. Elshansky, E.B. Puchkova, Yu.V. Suhovershina, Cognitive styles and personalization of education of students-psychologists, Vestnik of Minin University (2020)

28. M.L. Gruzdeva, N.I. Tukenova, Analysis of the current state of research and development in the construction of information and educational environments of higher educational institutions, Vestnik of Minin University (2019) 